Check for updates

Cite this: RSC Adv., 2019, 9, 36699

\title{
Apoferritin encapsulation of cysteine protease inhibitors for cathepsin L inhibition in cancer cells $\uparrow$
}

\author{
José C. Quilles Junior, ${ }^{\text {ab }}$ Fernanda dos Reis Rocho Carlos, ${ }^{b}$ A. Montanari, ${ }^{\text {b }}$ \\ Andrei Leitão, (D) b Viviane W. Mignone, ${ }^{\mathrm{C}}$ Maria Augusta Arruda, ${ }^{\mathrm{C}}$ \\ Lyudmila Turyanska (D) ${ }^{* d}$ and Tracey D. Bradshaw (D) *a
}

\begin{abstract}
Cysteine proteases play a key role in tumorigenesis causing protein degradation and promoting invasive tumour growth. Cathepsin L is overexpressed in cancer cells and could provide a specific target for delivery of anticancer agents. We encapsulated novel dipeptidyl nitrile based cysteine protease inhibitors (Neq0551, Neq0554 and Neq0568) into biocompatible apoferritin (AFt) protein nanocages to achieve specific delivery to tumours and $\mathrm{pH}$-induced drug release. AFt-encapsulated Neq0554 demonstrated $\sim 3$-fold enhanced in vitro activity $\left(\mathrm{Gl}_{50}=79 \mu \mathrm{M}\right)$ compared to naked agent against MiaPaCa-2 pancreatic carcinoma cells. Selectivity for cancer cells was confirmed by comparing their activity to nontumourigenic human fibroblasts $\left(\mathrm{Gl}_{50}>200 \mu \mathrm{M}\right)$. Transferrin receptor (TfR-1) expression, detected only in lysates prepared from carcinoma cells, may contribute to the cancer-selectivity. The $\mathrm{G}_{1}$ cell cycle arrest caused by AFt-Neq0554 resulting in cytostasis was corroborated by clonogenic assays. Superior and more persistent inhibition of cathepsin $\mathrm{L}$ up to $80 \%$ was achieved with AFt-encapsulated agent in HCT-116 cells following $6 \mathrm{~h}$ exposure to $50 \mu \mathrm{M}$ agent. The selective anticancer activity of AFtencapsulated cysteine protease inhibitor Neq0554 reported here warrants further preclinical in vivo evaluation.
\end{abstract}

Received 6th September 2019
Accepted 4th November 2019

DOI: $10.1039 / \mathrm{c} 9 \mathrm{ra07161j}$

rsc.li/rsc-advances

\section{Introduction}

Proteases are essential for cell survival and development and play important roles in cellular proliferation, migration, adhesion, senescence, autophagy, apoptosis and immune system evasion. ${ }^{2}$ To date, proteases were considered as potential targets for the treatment of diseases, such as Chagas disease, ${ }^{3}$ leishmaniosis, ${ }^{4}$ osteoporosis ${ }^{5}$ and some types of carcinomas. ${ }^{6-8}$ Predominantly found in the intracellular environment, these enzymes are abundantly localized in the lysosomes of normal cells. ${ }^{9}$ However, some proteases are also present in the extracellular medium, assisting extracellular matrix degradation in cancer. $^{2,10}$

Cathepsin L, a lysosomal cysteine protease, is a marker for, and overexpressed in pancreatic cancer. ${ }^{11,12}$ Because of the

${ }^{a}$ Centre for Biomolecular Sciences, School of Pharmacy, University of Nottingham, NG7 2RD,UK.E-mail: quilles@usp.br; tracey.bradshaw@nottingham.ac.uk

${ }^{b}$ Medicinal Chemistry Group (NEQUIMED), São Carlos Institute of Chemistry (IQSC), University of São Paulo, Av. Trabalhador São-carlense, 400, São Carlos, SP 13.566590, Brazil

'Queen's Medical Centre, School of Life Sciences, University of Nottingham, NG7 2RD, $U K$

${ }^{d}$ School of Physics and Astronomy, University of Nottingham, NG7 2RD, UK. E-mail: lyudmila.turyanska@nottingham.ac.uk

$\dagger$ Electronic supplementary information (ESI) available. See DOI: $10.1039 / \mathrm{c} 9 \mathrm{ra} 07161 \mathrm{j}$ aggressive nature of pancreatic cancers, $>80 \%$ of patients present with metastatic disease and 5 years survival is dismal, $\sim 8 \% .^{10,13}$ Colorectal adenocarcinoma (CRC) also represents an aggressive, chemotherapy-resistant disease. ${ }^{14}$ With high metastatic incidence $(>50 \%$ patients) and poor prognosis associated with late stage disease (5 years survival stage IV CRC $<8 \%$ ), therapeutic intervention has limited success. ${ }^{14}$ Cellular deregulation of cathepsin $\mathrm{L}$ expression is one of the common characteristics of these types of carcinomas, as well as elevated extracellular levels. ${ }^{15,16}$ Inhibition of cathepsin L could offer a route for treatment of these cancers. Recently, elevated cathepsin L activity has been reported in murine models with pancreatic cancer, with reduction in the tumour size after its gene deletion. ${ }^{13}$ Cathepsin $\mathrm{L}$ inhibition by covalent inhibitors was shown to suppress proliferation of pancreatic cancer cells, ${ }^{\mathbf{1 1}}$ and colorectal adenocarcinoma cells. ${ }^{14}$

Reversible covalent inhibitors are known to be a viable approach to decrease side effects associated with the off-target effects inside the cells. ${ }^{17}$ However, all types of covalent inhibitors need to position the reactive group in the vicinity of the cysteine amino acid in the catalytic pocket, thus leading to the necessity to design compounds with substituents that fit the subsites of the enzyme counterpart mimicking a peptide (peptidomimetics). One of the promising groups of peptidomimetic agents are dipeptidyl nitrile reversible covalent cysteine protease inhibitors with high-affinity for the target enzyme and 
potent human cathepsin $\mathrm{L}$ and cruzipain inhibition efficiency. ${ }^{18,19}$ Cathepsin $\mathrm{L}$ possesses important functions in normal cells, and its inhibition could cause adverse toxicities limiting therapeutic efficacy. Hence new formulations are needed to ensure selective or preferential uptake by cancer cells.

The apoferritin (AFt) nanocapsule has been identified as an ideal drug delivery vehicle ${ }^{20}$ and has been used to encapsulate proteins and small drug molecules. ${ }^{21-24} \mathrm{AFt}$ is internalized into cells by transferrin receptor 1 (TfR1)-mediated endocytosis; TfR1 is upregulated and highly expressed on cancer cell membranes. ${ }^{25}$ Also, enhanced delivery and uptake to cancer tissues is expected due to enhanced permeability and retention (EPR) associated with the tumour microenvironment. ${ }^{26}$ In the cells, AFt is trafficked to lysosomes, where increased acidity will increase the protein pore size releasing the cargo. ${ }^{\mathbf{2 4}}$ Since cathepsin $\mathrm{L}$ is found predominately within lysosomes, AFt could offer great potential for selective delivery of cysteine protease inhibitors.

Here we report the development of a new formulation of dipeptidyl nitrile derivatives for selective targeting to cancer cells and $\mathrm{pH}$ dependent drug release. We encapsulated cysteine protease inhibitors (Neq0551, Neq0554 and Neq0568) within AFt protein cages, demonstrating retention of AFt capsule structural integrity and formulation stability. Investigation of AFt formulations in physiologically relevant conditions revealed enhanced drug release under acidic $\mathrm{pH}$ 5.5, associated with tumour microenvironments, compared to neutral $\mathrm{pH}$ 7.4. In vitro assessment of antitumor activity of naked and AFtencapsulated agents against pancreatic and colorectal cancer cells was performed, confirming cancer-selectivity and enhanced potency of the developed formulation of these inhibitors. Our results provide the first demonstration of the potential of AFt for targeted delivery of cysteine protease inhibitors to cancer cells, relevant for their applications as anticancer agents in clinic.

\section{Materials and methods}

\section{Preparation and characterization of encapsulated compounds}

All the covalent reversible cysteine protease inhibitors were synthesized as previously reported. ${ }^{18}$ Agents, with purity $>95 \%$ according to HPLC-MS analysis, were selected based on their biochemical potential to inhibit cysteine proteases in the nanomolar range. Horse spleen AFt was diluted in sodium acetate buffer $100 \mathrm{mM} \mathrm{pH} 5.5$ at $6 \times 10^{-9}$ as final numbers of moles and kept at $4{ }^{\circ} \mathrm{C}$. Every $45 \mathrm{~min}$, the drugs dissolved in dimethylsulfoxide (DMSO) at the stock concentration of $50 \mathrm{mM}$ were gently added into the AFt solution to give a final ratio of $1: 500$ (AFt : drugs). Un-encapsulated compound was removed from solution by ultracentrifugation using Amicon membranes $30 \mathrm{kDa}\left(13000 \mathrm{rpm}, 4 \mathrm{~min}, 4^{\circ} \mathrm{C}\right.$ ). Neq compound concentration after purification of AFt-encapsulated compound was determined by UV-Vis absorbance at $248 \mathrm{~nm}$ using a Thermo Fisher Scientific NanoDrop ${ }^{\mathrm{TM}}$ 2000/c Spectrophotometer; the BeerLambert law was used to quantify encapsulation. Total protein concentration was determined using the Bradford assay. ${ }^{27}$ Encapsulation efficiency (EE\%) is calculated as the percentage of drug that is successfully entrapped into the apoferritin with respect to the drug added. Drug loading (DL\%) is calculated as the amount of drug loaded with respect to the total weight of the nanoparticle (apoferritin and encapsulated drug molecules).

All encapsulated drugs were aliquoted and stored at $4{ }^{\circ} \mathrm{C} \mathrm{pH}$ 5.5 and stability was examined throughout 6 weeks by UV-Vis spectroscopy. The physical properties of AFt were characterized by DLS and zeta-potential (using $1 \mathrm{~mL}$ of $0.2 \mathrm{mg} \mathrm{mL}{ }^{-1} \mathrm{AFt}$ encapsulated agent). Native PAGE was conducted to confirm AFt protein structure after encapsulation. Proteins, $15 \mu \mathrm{L} \mathrm{AFt} \mathrm{solu-}$ tions $\left(\sim 0.2 \mathrm{mg} \mathrm{mL}^{-1}\right)$ were separated on a $4-16 \%$ gradient gel (Novex) at $4{ }^{\circ} \mathrm{C}$ using cathodic and anodic buffers. Proteins were stained following immersion of gels in Coomassie brilliant blue for $1 \mathrm{~h}$ and washed with deionized water before capture of images using Gene flow limited. Drug release was analyzed in vitro in acidic (sodium acetate $100 \mathrm{mM} \mathrm{pH} \mathrm{5.5)} \mathrm{and} \mathrm{neutral}$ (Hepes buffer $100 \mathrm{mM}$ pH 7.4) pH conditions. A dialysis method was selected using a dialysis membrane (cut-off $8 \mathrm{kDa}$ ) for $24 \mathrm{~h}$ at $37{ }^{\circ} \mathrm{C}$. At different time points, drug release was determined by UV-Vis, considering the initial concentration of encapsulated drug as $100 \%$.

\section{In vitro studies}

HCT-116 (hMLH1-) colorectal carcinoma cells and MiaPaCa-2 pancreatic adenocarcinoma cells were purchased from the American type culture collection (ATTC) and grown in RPMI1640 medium supplemented with $10 \%$ foetal bovine serum (FBS). For MRC-5 human fibroblast cells, DMEM medium modified with $1 \%$ antibiotics, $1 \%$ non-essential amino acids, $5 \mathrm{mM}$ L-glutamine, $1 \mathrm{mM}$ HEPES buffer and 10\% FBS was used. All cell lines were grown at $37{ }^{\circ} \mathrm{C}, 5 \% \mathrm{CO}_{2}$ and used for the assays after achieving 70\% confluence. The MTT [3-(4,5dimethylthiazol-2-yl)-2,5-diphenyltetrazolium bromide] assay was used for cell growth and viability determination of normal and cancer cell lines after treatment with naked and encapsulated drugs at different concentrations. Cells were seeded into 96-well plates at density of $3 \times 10^{3}$ per well. The MTT reduction at the time of drugs' addition $\left(T_{0}\right)$ and following $72 \mathrm{~h}$ exposure was assessed to determine growth inhibitory effects.

The clonogenic cell survival test was adopted to determine the ability of single cells to survive a brief exposure to test agents and maintain proliferative potential to form progeny colonies. For this study, the cells (300 per well) were seeded into 6-well plates and test agent treatment was performed for $24 \mathrm{~h}$ using naked and encapsulated compounds at $10 \mu \mathrm{M}$ and $100 \mu \mathrm{M}$. After 7 days of incubation, colonies were stained with $0.5 \%$ methylene blue.

\section{Cell cycle study}

For cell cycle analysis cell were seeded in 6 well plates at a seeding density of $5 \times 10^{5}$ cells per well in $2 \mathrm{~mL}$ medium. Following treatment with naked and encapsulated Neq0554 at final concentration of $10 \mu \mathrm{M}$ and $100 \mu \mathrm{M}$, cells were pelleted by centrifugation then resuspended in $0.5 \mathrm{~mL}$ fluorochrome solution $50 \mu \mathrm{g} \mathrm{mL}^{-1}$ propidium iodide (PI), $0.1 \mathrm{mg} \mathrm{mL}^{-1}$ ribonuclease A, $0.1 \% \mathrm{v} / \mathrm{v}$ Triton $\mathrm{X}-100$, and $0.1 \% \mathrm{w} / \mathrm{v}$ sodium citrate 
in deionized water $\left(\mathrm{dH}_{2} \mathrm{O}\right)$. Cell suspensions were kept overnight at $4{ }^{\circ} \mathrm{C}$ protected from light. Cell cycle analyses were performed on a Beckman Coulter FC500 flow cytometer. EXPO32 software was used to analyze data.

\section{Enzymatic studies}

Cathepsin L isolated from human liver (Enzo life sciences) was assayed fluorometrically using the system Biotek Synergy HT at $25{ }^{\circ} \mathrm{C}$ with a fluorescence emission of $460 \mathrm{~nm}$ (excitation of 355 $\mathrm{nm}$ ) over 5 minutes. The hydrolysis rate of the fluorogenic substrate Z-Phe-Arg-7-amido-4-methylcoumarin (Z-FR-MCA, Sigma-Aldrich) was monitored. Enzyme kinetic assays were carried out in Corning 96-well black flat bottom microplates containing $200 \mu \mathrm{L}$ of a solution constituted by $100 \mathrm{mM}$ acetate buffer pH 5.5, $300 \mathrm{mM} \mathrm{NaCl}, 7 \mathrm{mM}$ DTT (dithiothreitol), 5\% v/v DMSO, $0.01 \% \mathrm{v} / \mathrm{v}$ TritonX-100 and $1.9 \mathrm{nM}$ hCat-L. The enzyme was activated for $20 \mathrm{~min}$ in the assay buffer $(100 \mathrm{mM}$ acetate $\mathrm{pH}$ 5.5 and $7 \mathrm{mM}$ DTT) before the reaction started. The substrate ZFR-MCA was prepared with a final concentration of $10.9 \mu \mathrm{M}(=4$ $\left.\times K_{\mathrm{M}}\right)$. Stock solutions of the inhibitors were prepared in DMSO with initial concentrations varying from 1 to $10 \mu \mathrm{M}$. The assay was performed in triplicate. Analysis and manipulation of the data were performed with Origin Pro 8.5. Each experiment was performed in triplicate for each substance. Initial velocities of the substrate hydrolysis under the first-order reaction were calculated using Gen5 ${ }^{\mathrm{TM}}$ Biotek software. The apparent inhibition constant $K_{\mathrm{i}}^{\prime}$ was determined by non-linear regression using equation $V_{\mathrm{s}}=V_{\mathrm{o}} /\left(1+[\mathrm{I}] / K_{\mathrm{i}}^{\prime}\right)$, where $V_{\mathrm{s}}$ is the steady-state rate, $V_{\mathrm{o}}$ is the rate in the absence of inhibitor, and [I] is the inhibitor concentration. The true inhibition constant $K_{\mathrm{i}}$ was calculated by the correction of $K_{\mathrm{i}}^{\prime}$ according to $K_{\mathrm{i}}=K_{\mathrm{i}}^{\prime} /\left([\mathrm{S}] / K_{\mathrm{M}}\right)$, where $[\mathrm{S}]$ is the substrate concentration and $K_{\mathrm{M}}$ is the Michaelis constant.

\section{Western blot}

Cells were cultured in $75 \mathrm{~cm}^{2}$ flasks at $37{ }^{\circ} \mathrm{C}, 5 \% \mathrm{CO}_{2}$ until $\sim 70 \%$ confluent. Cells were then detached by trypsin and lysed using lysis buffer (100 mL NP40, $1 \mathrm{M} \mathrm{NaCl}, 1 \mathrm{M}$ Tris-HCl pH 8.0) supplemented with a protease inhibitor cocktail (Roche). Cellular proteins $(50 \mu \mathrm{g})$ were separated by sodium dodecyl sulfate-polyacrylamide gel electrophoresis (SDS-PAGE), and electro-transferred onto PVDF membranes blocked in Trisbuffered saline (TBS) solution containing $5 \%$ milk at room temperature. Membranes were incubated in primary antibodies $\left(1^{\circ} \mathrm{Abs}\right.$; GAPDH and TfR-1) overnight at $4{ }^{\circ} \mathrm{C}$. Membranes were then washed with TBS solution at room temperature and incubated with a secondary $\left(2^{\circ}\right) \mathrm{Ab}(\mathrm{GE})$ for $1 \mathrm{~h}$. Detection was performed with Super Signal chemiluminescent reagent according to the manufacturer's protocol (Tanon, China).

\section{Confocal fluorescence microscopy}

Cells were seeded into 96-well black plates at a density of $10^{4}$ cells per well and treated with $100 \mu \mathrm{M}$ of naked and encapsulated compounds for $24 \mathrm{~h}$. Cells were washed with PBS and incubated for $1 \mathrm{~h}$ with $300 \times$ diluted Red Magic Substrate (Sigma-Aldrich) and Hoechst as a nuclear marker. Fluorescence images were acquired with a confocal microscope Ultra Nikon equipped with a $40 \times$ objective with excitation filters at 510$560 \mathrm{~nm}$. Fluorescence emission was detected using bandpass filter at 570-620 nm. Non-treated cells and cells treated with AFt alone were used as negative controls.

\section{Results}

\section{Encapsulation and characterization of AFt-Neq test agents}

The dipeptidyl nitriles derivatives were synthesized as described ${ }^{18}$ and agents were selected for this study based on their biochemical potential to inhibit cysteine proteases in the nanomolar range. Three reversible covalent cysteine protease inhibitors based on dipeptidyl nitrile were used: Neq0551 ((2S)- $N$-(cyanomethyl)-3-(4-hydroxyphenyl)-2-(phenylformamido)propenamide); Neq0554 ((2S)-N-(cyanomethyl)-2-\{[1-methyl-3-(trifluoromethyl)$1 H$-pyrazol-5-yl]formamido\}-3-phenylpropanamide) and Neq0568 ((2S)-2-[(3-tert-butyl-1-methyl-1 $H$-pyrazol-5-yl)formamido]- $N$-(cyanomethyl)-4-methylpentanamide) (Fig. 1a). All agents were encapsulated into the AFt cage by passive diffusion through the six hydrophobic channels in the protein cage (Fig. 1b). ${ }^{28}$

For encapsulations, all agents were dissolved in DMSO (10 $\mathrm{mM}$ ). Horse spleen AFt was prepared with a concentration of $\sim 5 \mathrm{mM}$ and was dialyzed against sodium acetate buffer $(\mathrm{pH}$

(a)<smiles>N#CCNC(=O)C(Cc1ccc(O)cc1)NC(=O)c1ccccc1</smiles><smiles>CC(C)(C)OC(=O)NC(Cc1cccc(Cl)c1)C(=O)NCC#N</smiles><smiles>CC1CC(NC(=O)c2cc(C(C)(C)C)nn2C)C(=O)N1C(=O)C#N</smiles>

(b)

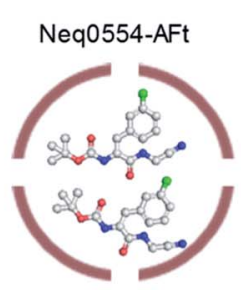

(c)
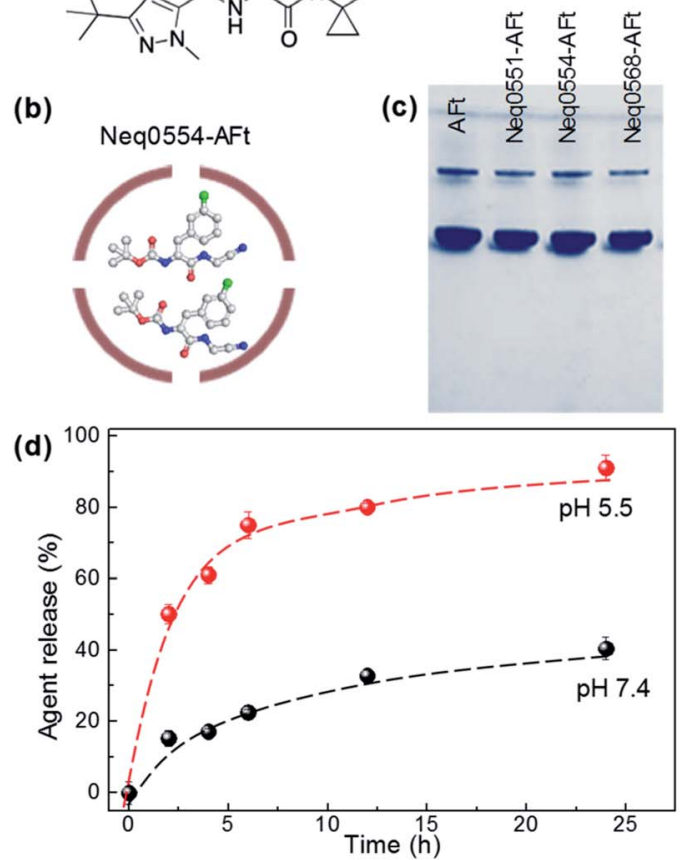

Fig. 1 (a) Chemical structures of the test agents. (b) A schematic representation of encapsulated agent, Neq0554-AFt. (c) A photograph of native PAGE of AFt and AFt-encapsulated agents. (d) Drug release profile for Neq0554-AFt at $\mathrm{pH} 5.5$ and $\mathrm{pH} 7.4$ at $T=37^{\circ} \mathrm{C}$. 
5.5). For encapsulation, $100 \mu \mathrm{L}$ of agent was added ten times (with intervals of $45 \mathrm{~min}$ between additions) to $1 \mathrm{~mL}$ of apoferritin under constant mixing at $4{ }^{\circ} \mathrm{C}$. The final molar ratio of AFt : agent was $1: 500$. The encapsulation of test agents was assessed by UV-Vis and the drug concentration was quantified according to the Beer-Lambert law.

The mean numbers of encapsulated Neq0554 and Neq0551 molecules were 105 and 117, respectively, corresponding to encapsulation efficiencies (EE) $>50 \%$ and drug loading $>10 \%$. For Neq568, the EE was $71 \%$ and the mean number of molecules encapsulated was 226 (Table 1).

Following encapsulation, AFt retained its structural integrity, as confirmed by native PAGE $^{29}$ and dynamic light scattering (DLS), revealing the AFt band corresponding to MW $\sim 480 \mathrm{kDa}$ (Fig. 1b) and protein cage diameter of $\sim 13 \mathrm{~nm}$ (Fig. 1c), respectively, as expected for $\mathrm{AFt}^{30}$ The value of the zetapotential measured for AFt alone was $-8.6 \pm 0.8 \mathrm{meV}$, and was not changed following encapsulation of test agents $(-8.6 \pm$ $0.7 \mathrm{meV}$ for Neq0554-AFt, $-8.5 \pm 0.5 \mathrm{meV}$ for Neq0551-AFt, -8.9 $\pm 0.2 \mathrm{meV}$ for Neq0568-AFt). These results confirm that the agents are encapsulated predominantly inside the AFt cavity. We have studied the release rate for all our encapsulated agents at physiologically relevant $\mathrm{pH} 7.4$ and $\mathrm{pH}$ 5.5. We observed markedly more rapid release of cargo at $\mathrm{pH} 5.5$ compared to physiological $\mathrm{pH}$ 7.4, with corresponding out-diffusion of Neq0554 $>75 \%$ and $\sim 32 \%$ respectively after $12 \mathrm{~h}$ dialysis (Fig. 1d). This trend was observed for all test agents (Fig. SI-2 $\dagger$ ). In addition, at $\mathrm{pH} 5.5$, initial fast release was more evident with $>50 \%$ compound liberated in the first $6 \mathrm{~h}$.

\section{Biological activity of AFt-Neq test agents}

The therapeutic activity of the test agents and their encapsulated formulations was evaluated in vitro. For these studies the following cell lines were selected: HCT-116 (CRC) and MiaPaCa2 (pancreatic) carcinoma cell lines, MRC-5 foetal fibroblasts representative of a non-transformed phenotype. Neq0551, Neq0554 and Neq0568 agents were shown to possess modest growth inhibitory activity against HCT-116 and MiaPaCa-2 carcinoma cells with $\mathrm{GI}_{50}$ values $\sim 400 \mu \mathrm{M}$. Selectivity for cancer cells over MRC-5 fibroblasts was unremarkable with maximum cancer selectivity indices achieved for Neq0554 and Neq0568 of 1.75 and $\sim 2$ respectively $\left(\mathrm{GI}_{50} \mathrm{MRC}-5 / \mathrm{GI}_{50} \mathrm{MiaPaCa}-\right.$ 2 or HCT-116). AFt-encapsulated test agents showed greater growth inhibitory activity in cancer cells, compared to the naked

Table 1 Summary of encapsulation efficiency (EE) and drug loading (DL) for cysteine protease inhibitors. Number of molecules of test agent per AFt capsule was determined by UV-vis spectroscopy. All measurements were performed in triplicate and the standard deviation (SD) is provided

\begin{tabular}{lllll}
\hline & Chemical formula & $N$ (per AFt) & EE (\%) & DL (\%) \\
\hline Neq0551 & $\mathrm{C}_{18} \mathrm{H}_{17} \mathrm{~N}_{3} \mathrm{O}_{3}$ & $117 \pm 3$ & $55.2 \pm 4.6$ & $14.5 \pm 4.4$ \\
Neq0554 & $\mathrm{C}_{17} \mathrm{H}_{16} \mathrm{~F}_{3} \mathrm{~N}_{5} \mathrm{O}_{2}$ & $105 \pm 2$ & $50.9 \pm 10.9$ & $10.1 \pm 1.2$ \\
Neq0568 & $\mathrm{C}_{17} \mathrm{H}_{27} \mathrm{~N}_{5} \mathrm{O}_{2}$ & $226 \pm 12$ & $71.2 \pm 9.9$ & $14.3 \pm 6.8$
\end{tabular}
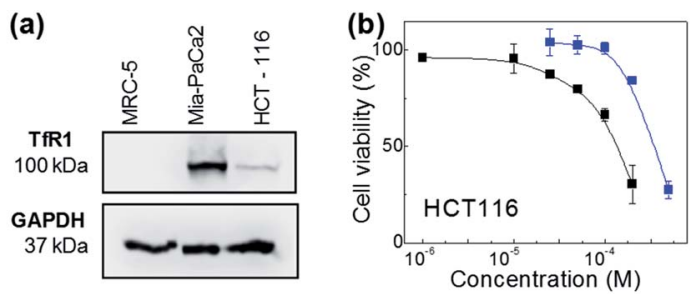

(c)

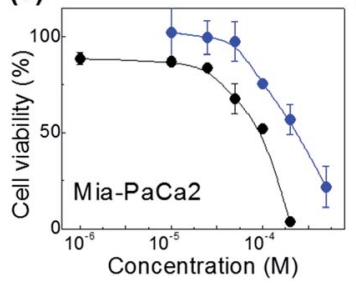

(d)

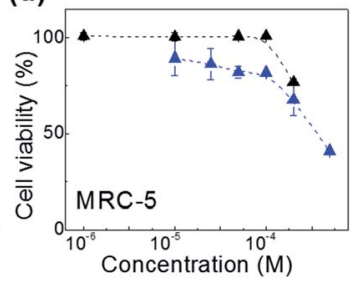

Fig. 2 Western blot image revealing expression of transferrin receptor (TfR1) in MiaPaCa-2 and HCT-116 cancer cells (a). Dose response profiles of naked- and AFt-encapsulated Neq0554 in (b) HCT-116, (c) MiaPaCa- 2 cancer cells and (d) MRC-5 fibroblasts. Cell viability assays were performed in triplicate ( $n=4$ per trial) and the standard deviation $(\mathrm{SD})$ is shown. Lines are a guide to the eye.

compounds. In particular, following $72 \mathrm{~h}$ exposure to carcinoma cells, $>2.5$-fold enhanced Neq0554 potency was achieved for encapsulated agent; against MiaPaCa-2 cells, $\mathrm{GI}_{50}$ value $<80$ $\mu \mathrm{M}$ for AFt-Neq0554 (Fig. 2). AFt-encapsulation of Neq0568 reduced the $\mathrm{GI}_{50}$ value $>3$-fold in MiaPaCa-2 cells (Table 2). Importantly, selectivity for cancer cells became more pronounced for encapsulated agents with $\mathrm{GI}_{50}$ values of $>200$ $\mu \mathrm{M}$ in non-tumorigenic MRC-5 fibroblasts.

AFt is internalized by cells by TfR1-mediated endocytosis, ${ }^{25}$ hence western blot was performed to investigate cellular TfR-1 levels. TfR1 protein expression was detected in lysates prepared from HCT-116 and MiaPaCa- 2 cells; in contrast, TfR1 levels were undetectable in lysates of non-tumorigenic fibroblasts, inferring disparity in TfR1 expression between cancer and non-cancer cells (Fig. 2d). Indeed, rapid cell division increases cellular iron demand and enhanced TfR1 expression is detected in cancer cells. ${ }^{25}$ Preferential expression of TfR 1 by actively dividing cells, including normal fibroblasts, was reported $>30$ years ago, ${ }^{31}$ as transferrin is required for cell proliferation in culture.

Table $2 \mathrm{Gl}_{50}$ values for both naked and AFt-encapsulated drugs tested against the cancer and normal cell lines

\begin{tabular}{llll}
\hline \multicolumn{4}{l}{ Mean $\mathrm{GI}_{50}$ values $\pm \mathrm{SD}(\mu \mathrm{M})$} \\
\cline { 2 - 4 } Test agent & HCT-116 & MiaPaCa-2 & MRC-5 \\
\hline Neq0551 & $>500$ & $>500$ & $>500$ \\
Neq0551-AFt & $>200$ & $162.2( \pm 5.7)$ & $>200$ \\
Neq0554 & $358.6( \pm 7.7)$ & $230.7( \pm 9.1)$ & $404.0( \pm 9.7)$ \\
Neq0554-AFt & $131.0( \pm 5.2)$ & $79.5( \pm 10.7)$ & $>200$ \\
Neq0568 & $231.1( \pm 7.8)$ & $393.0( \pm 8.1)$ & $>500$ \\
Neq0568-AFt & $168.1( \pm 6.5)$ & $125.1( \pm 9.8)$ & $>200$
\end{tabular}


(a)

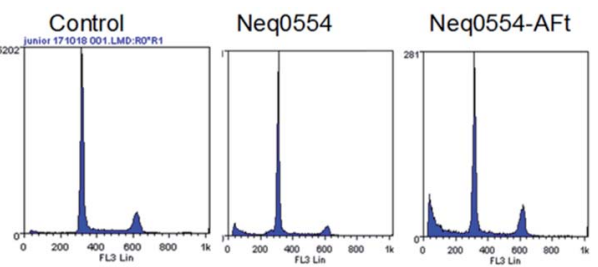

(b)

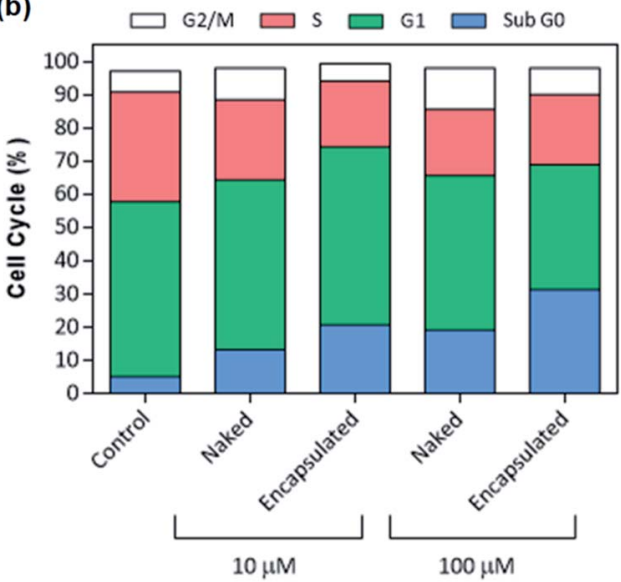

Fig. 3 (a) Representative cell cycle profiles of HCT-116 cells and (b) histogram of the cell population distribution for control cells and following treatment with naked and encapsulated Neq0554. The standard deviation was calculated and was found to be $<5 \%$.

To better understand the mechanism of carcinoma cell growth inhibition caused by AFt-Neq0554 compared to naked agent, cell cycle was examined by flow cytometry. Following $48 \mathrm{~h}$ treatment, MiaPaCa-2 and HCT-116 cells were gently permeabilized and cellular DNA was stained with propidium iodide (PI). Although changes in $\mathrm{G}_{1}, \mathrm{G}_{2}$ and $\mathrm{M}$ phase-events were modest, the population of cells in S-phase was reduced by $\sim 15 \%$ in HCT 116 cells following treatment with AFt encapsulated agent AFt-Neq0554 $(10 \mu \mathrm{M})$. These results suggest reduced DNA replication and cytostasis/quiescence. Also, following exposure of cancer cells to both naked and encapsulated agents, small but significant pre G1 phase populations were observed, indicating apoptosis. Representative cell cycle profiles for HCT 116 (Fig. 3) show $14 \%$ and $26 \%$ of pre- $\mathrm{G}_{1}$ events following exposure to $10 \mu \mathrm{M}$ and $100 \mu \mathrm{M}$ AFt-encapsulated Neq 554, respectively.

Clonogenic assays were performed to explore further the putative cytotoxicity caused by AFt-Neq0554, examining whether cells surviving exposure to the test agents retain the ability to form colonies. The clonogenic survival of HCT 116 cells was marginally inhibited ( $22 \%$ and $28 \%$ ) by $24 \mathrm{~h}$ exposure to $100 \mu \mathrm{M}$ naked and AFt-encapsulated Neq0554, respectively. In contrast, MiaPaCa-2 colony formation was dramatically impeded $(>60 \%)$ by naked and AFt-encapsulated Neq0554 (100 $\mu \mathrm{M})$. In both cell lines, AFt-encapsulated Neq554 inhibited colony formation to a greater extent than naked agent, likely due to enhanced cellular uptake. That colony formation persisted, strongly indicates a cytostatic response to treatment, temporary quiescence dependent upon presence of the compound.

\section{Cathepsin $\mathrm{L}$ inhibition analysis by confocal microscopy}

Cells were exposed to different concentrations of naked and encapsulated Neq0554 for 6 and 24 h to examine cathepsin L inhibition inside live cells. In both cancer cell lines, total cathepsin L activity was more effectively inhibited following exposure to AFt-encapsulated agent, compared to naked Neq0554. AFt alone had no effect on cathepsin L activity. At treatment concentrations of Neq554 above $25 \mu \mathrm{M}$, inhibition of cathepsin L by AFt-encapsulated agent was $>50 \%$ after $6 \mathrm{~h}$ exposure (Fig. 4). Although some recovery of activity was observed after $24 \mathrm{~h}$ treatment, cathepsin L inhibition $>20 \%$ did persist. This trend was also observed in MiaPaCa-2 cells. Of note was the observation that after $24 \mathrm{~h}$ exposure of cells to naked Neq0554, no inhibition of cathepsin $\mathrm{L}$ was detected in either cell line, activity equivalent to untreated control cells was observed (not shown) strongly inferring that AFt-encapsulation prolonged cathepsin L inhibition, potentially by retaining intracellular/lysosomal Neq554 for a greater period of time.

All inhibitors used here were designed based on a dipeptidyl nitrile structure as prototype. ${ }^{19}$ Using biochemical analysis, we were able to measure the affinity of these drugs to their molecular target: cathepsin L. The apparent inhibition constant $K_{\mathrm{i}}^{\prime}$ was determined by non-linear regression to be $7.10 \pm 0.04$, $7.90 \pm 0.04$ and $8.10 \pm 0.03$ for Neq0551, Neq0554 and Neq0568, respectively. We observed that all compounds were potent inhibitors of cathepsin L activity based on an in vitro assay, with $K_{\mathrm{i}}^{\prime}$ lower than $10 \mathrm{nM}$. Biochemical affinity has been
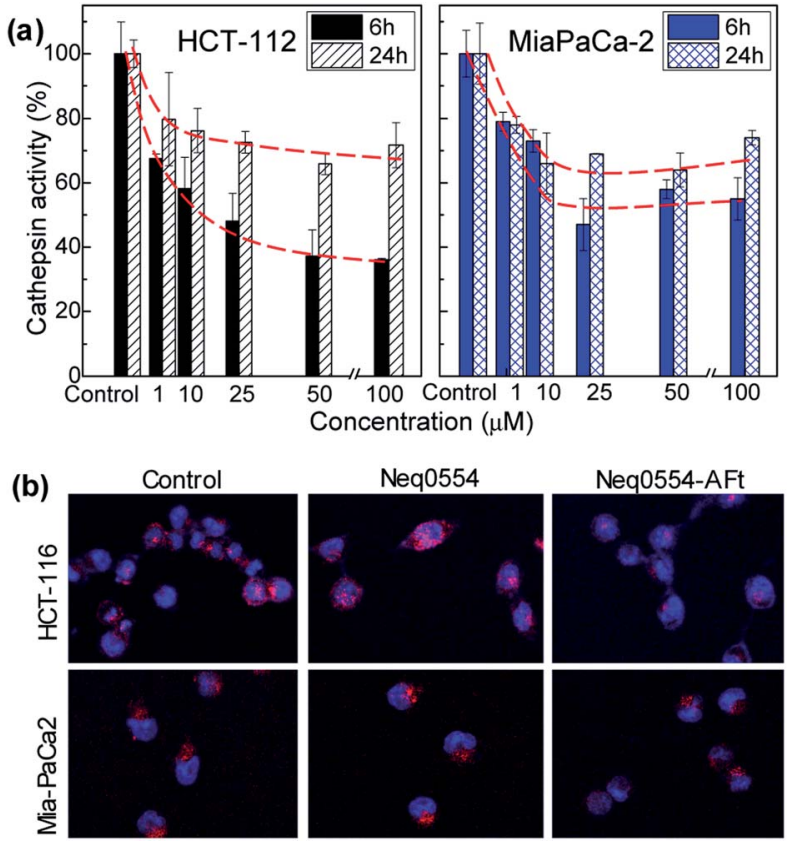

Fig. 4 Cathepsin L in vitro activity in HCT 116 and MiaPaCa-2 cells following $6 \mathrm{~h}$ or $24 \mathrm{~h}$ exposure to AFt-Neq554. Data were generated following quantification of confocal microscopy images and represent mean $\pm S D \geq 3$ independent trials (a). Confocal images of HCT 116 and MiaPaCa-2 cells after $6 \mathrm{~h}$ incubation of $50 \mu \mathrm{M}$ naked and AFtencapsulated Neq554, for comparison, images of untreated control cells are also shown (b). All images are $100 \mu \mathrm{m}$ wide. 
corroborated with observations of cellular cathepsin L inhibitory activity in real time.

\section{Discussion}

The loading of the cysteine protease inhibitor in AFt nanocages was performed by passive diffusion, where agents enter the cage via channels in the AFt capsule. Following encapsulation, the samples are purified to remove non-encapsulated drug molecules. We assessed the morphology of encapsulated agents by DLS and native PAGE, confirming that the external diameter and surface charge of the AFt remains unchanged following encapsulation. We also note, that enhanced intracellular internalisation of AFt-encapsulated agent is strongly supported by our in vitro studies and confocal microscopy imaging of cathepsin $\mathrm{L}$ inhibition. These observations strongly suggest that the protein remains unchanged following the encapsulation process. Hence, we conclude that all molecules detected in our samples are in the inner cavity of the protein.

The covalent reversible cysteine protease inhibitors used in this work were reported previously as experimental putative anticancer agents, ${ }^{18,19}$ however their selectivity to cancer cell lines needed to be addressed to reduce potential toxicities and side effects. All compounds are dipeptidyl nitrile derivatives (Fig. 1a). The cysteine protease inhibition occurs by interaction of nitrile group with the sub sites present in the enzyme structure, promoting the attack of the nitrile group by the nucleophilic Cys25 in the catalytic pocket of the cysteine protease.

Based on previous results from our group, the nanomolar inhibition of the cysteine proteases did not lead to relevant cytotoxic activity at $100 \mu \mathrm{M}$ in cell-based assays against the Leishmania spp. parasites 30 or pancreatic carcinoma cells (MiaPaCa-2). ${ }^{30,32}$ Therefore, AFt encapsulation was used to enhance the cytotoxic potential against cancer cells. Since the test agents are hydrophobic (Fig. 1a), we envisage that encapsulation takes place via passive diffusion through the hydrophobic channels in the protein cage (Fig. 1b) in which EE $>50 \%$ was achieved for all compounds. Also, the surface charge of the AFt nanocapsules was not affected following the encapsulation procedure, suggesting that the molecules are incorporated within the cavity and are not attached to the protein capsules' exterior (Fig. 1c), hence the cellular recognition and uptake of AFt is not expected to be affected by the presence of internalized agent.

An additional benefit of the AFt formulation arises from the $\mathrm{pH}$ sensitivity of the protein capsule, ${ }^{33}$ which can be employed for favourable $\mathrm{pH}$ controlled drug release under specific conditions. Our release studies confirmed that at reduced $\mathrm{pH}$ values associated with increased size of the AFt channels $(\mathrm{pH}$ $5.5),{ }^{34,35}$ the release of the agent is enhanced by a factor of 4 compared to pH 7.4 (Fig. 1d and ESI, Fig. S2 $\dagger$ ), similar to that demonstrated for doxorubicin. ${ }^{35}$ In contrast, markedly reduced drug release was obtained at physiological pH (Fig. 1d). Previous reports also indicated long-term retention of encapsulated agents at $\mathrm{pH} 7 .^{34,35}$ Our results confirm that the drug encapsulated within AFt nanocages will be preferentially released in acid environments such as those within the cancer microenvironment and specifically, intracellular lysosomes. ${ }^{36}$

We posit that AFt provides a biocompatible carrier, indeed, no cytotoxic activity of AFt alone was observed in any of the studied cell lines (Fig. SI-2†), consistent with work reported previously. ${ }^{37}$ In addition, encapsulation of biomolecules into AFt nanocages has excellent potential in terms of enhanced drug accumulation, cellular uptake and biological activity. ${ }^{38}$

AFt is preferentially internalized by cells following TfR1mediated endocytosis, ${ }^{25}$ hence AFt encapsulation of active agent provides a tool for their selective uptake by cells expressing TfR1, hence decreasing possible side effects. ${ }^{34}$ Cellular TfR-1 protein was detected in lysates of HCT-116 and MiaPaCa-2 cancer cells, and was below detectable levels in nontumorigenic fibroblast MRC-5 cells (Fig. 2a). This difference in TfR1 expression is a likely cause of the improved potency against cancer cells of all test agents after AFt-encapsulation. Also, selectivity indices for Neq compounds are clearly enhanced between cancer and non-cancer cells, as evident from the dose response curves (Fig. 2b-d). Following exposure of cancer cells to both naked and encapsulated Neq0554, increased pre-G1 phase populations were observed (Fig. 3), indicating apoptosis. ${ }^{39,40}$

Cell survival and clonogenic expansion are fundamental to cancer development and metastases. ${ }^{41,42}$ Clonogenic assays were therefore performed to explore further putative cytotoxicity imparted by AFt-Neq0554, examining whether cells surviving exposure to the test agents retain the ability to form colonies. In both studied cancer cell lines, AFt facilitated increase of cellular uptake of the agent led to inhibition of colony formation to a greater extent than naked agent. Clonogenic survival was significantly lower in MiaPaCa-2 compared to HCT-116 cells. In addition, colonies of reduced size were observed following treatment of cells with AFt-encapsulated agents. Indeed, cysteine protease inhibition is expected to decrease cell migration and invasion, ${ }^{8}$ key cancer hallmarks essential for metastasis.

Inhibitors of proteases have shown in vitro and in vivo anticancer activity, promoting beneficial effects for the treatment of tumours. ${ }^{43}$ Herein, we demonstrate that cathepsin L inhibition was markedly enhanced in both cell lines after exposure to AFt-Neq0554. These observations corroborate a role for TfR1mediated uptake of AFt-encapsulated agents and sustained release of cargo in acidic lysosomes, indicating the significance of AFt nanocage-encapsulation to potentiate treatment efficacy by exploitation of cancer cell upregulation of TfR1. It is noteworthy that in MiaPaCa-2 cells, where cathepsin L inhibition persisted for $24 \mathrm{~h}$, clonogenic survival, following $24 \mathrm{~h}$ exposure of cells to AFt-Neq0554 was $<40 \%$, thus inferring that the cysteine protease inhibition is intensified by encapsulation of the inhibitors in AFt, which traffics cargo directly to the lysosomes, where these enzymes predominate. ${ }^{44}$ Cathepsin L inhibition was demonstrated previously using small molecule inhibitors, ${ }^{7}$ antisense RNA $^{45}$ and (si)RNA. ${ }^{46}$ The anticancer activity of AFt-encapsulated dipeptidyl nitrile based inhibitors is comparable to the activity of other small molecule inhibitors, ${ }^{7}$ and offers additional benefit of $\mathrm{pH}$ induced release and 
selective uptake. Inhibition of cathepsin L achieved in this work is of particular importance for pancreatic cancer treatment, where cathepsin $\mathrm{L}$ is considered to be an independent prognostic marker, ${ }^{47}$ and its inhibition could be used to reduce cancer invasion and tumor growth, and merits further investigations in vivo.

\section{Conclusions}

In conclusion, we have developed a robust method for encapsulation of novel Neq cathepsin L inhibitors into AFt nanocages: $>100$ Neq0554 molecules were encapsulated per AFt cage achieving $>50 \% \mathrm{EE}$. The integrity of AFt nanocages was preserved as evidenced by DLS and native PAGE. Encapsulated Neq0554 demonstrated enhanced anticancer activity in vitro compared to naked agent (3-fold), revealing cancer cell lineselectivity (2.5-fold), possible consequence of enhanced TfR-1mediated endocytosis of AFt-Neq0554. Increased and more persistent inhibition of cathepsin $\mathrm{L}$ in treated cancer cells was observed following AFt-encapsulation of Neq0554, consistent with cellular retention and sustained release of Neq0554 in acidic cytosolic compartments. Release of all Neq cathepsin L inhibitors, determined under physiological conditions demonstrated more rapid liberation from AFt capsules in acidic environments analogous to those found in lysosomes. We conclude that AFt-mediated delivery of novel cathepsin L inhibitors is worthy of further pursuit as a putative anticancer strategy.

\section{Conflicts of interest}

All the authors confirm there are no conflicts to declare.

\section{Acknowledgements}

This study was supported by the National Centre for the Replacement, Refinement and Reduction of Animals in Research [grant number NC/L001861/1]; the Engineering and Physical Sciences Research Council [grant numbers EP/ K503800/1]; and the Coordenação de Aperfeiçoamento de Pessoal de Nível Superior - Brasil (CAPES - University of Nottingham Programme in Drug Discovery) - Finance code 139/2015. Also, authors thank for the São Paulo Research Foundation support (FAPESP, grant numbers: 2014/07292-0, 2013/18009-4).

\section{References}

1 M. Drag and G. S. Salvesen, Nat. Rev. Drug Discovery, 2010, 9, 690-701.

2 C. López-Otín and L. M. Matrisian, Nat. Rev. Cancer, 2007, 7, 800-808.

3 S. Gea, A. Pellegrini and A. Cruzipain, Inmunologia, 2006, 25, 225-238.

4 R. A. Williams, L. Tetley, J. C. Mottram and G. H. Coombs, Mol. Microbiol., 2006, 61(3), 655-674.

5 J. Y. Gauthier, N. Chauret, W. Cromlish, S. Desmarais, et al., Bioorg. Med. Chem. Lett., 2008, 18, 923-928.
6 V. Lyo, F. Cattaruzza, T. N. Kim, A. W. Walker, M. Paulick, D. Cox, J. Cloyd, J. Buxbaum, J. Ostroff, M. Bogyo, et al., Am. J. Physiol. Gastrointest. Liver Physiol., 2012, 303, G894G903.

7 D. R. Sudhan and D. W. Siemann, Pharmacol. Ther., 2015, 155, 105-116.

8 R. Colella, T. Jackson and E. Goodwyn, Biotech. Histochem., 2015, 79(3-4), 121-127.

9 H.-H. Otto and T. Schirmeister, Chem. Rev., 1997, 97(1), 133172.

10 N. Singh, P. Das, S. Gupta, V. Sachdev, S. Srivasatava, S. Datta Gupta, R. M. Pandey, P. Sahni, S. S. Chauhan and A. Saraya, World J. Gastroenterol., 2014, 20(46), 17532-17540.

11 J. A. Joyce, A. Baruch, K. Chehade, N. Meyer-Morse, E. Giraudo, F. Tsai, D. C. Greenbaum, J. H. Hager, M. Bogyo and D. Hanahan, Cancer Cell, 2004, 5, 443-453.

12 M. M. Mohamed and B. F. Sloane, Nat. Rev. Cancer, 2006, 6, 764-775.

13 N. R. Brindle, J. A. Joyce, F. Rostker, E. R. Lawlor, L. SwigartBrown, G. Evan, D. Hanahan and K. Shchors, PLoS One, 2015, 10, 1-17.

14 T. Tamhane, R. Lllukkumbura, S. Lu, G. M. Maelandsmo, M. H. Haugen and K. Brix, Biochimie, 2015, 122, 208-218.

15 C. Palermo and J. Joyce, Trends Pharmacol. Sci., 2008, 29, 2228.

16 V. Gocheva, W. Zeng, D. Ke, D. Klimstra, T. Reinheckel, C. Peters, D. Hanahan and J. A. Joyce, Genes Dev., 2006, 20, 543-556.

17 T. A. Baillie, Angew. Chem., Int. Ed., 2016, 55, 13408-13421. 18 L. A. A. Avelar, C. D. Camilo, S. de Albuquerque, W. B. Fernandes, C. Gonçalez, P. W. Kenny, A. Leitão, J. H. McKerrow, C. A. Montanari, E. V. M. Orozco, et al., PLoS Neglected Trop. Dis., 2015, 9, 1-24.

19 J. C. Jr Quilles, M. D. L. Bernardi, P. H. J. Batista, S. C. M. Silva, C. M. R. Rocha, C. A. Montanari and A. Leitão, Anti-Cancer Agents Med. Chem., 2019, 19, 112-120. 20 C. Roney, P. Kulkarni, V. Arora, P. Antich, F. Bonte, A. Wu, N. N. Mallikarjuana, S. Manohar, H. F. Liang, A. R. Kulkarni, H. W. Sung, M. Sairam and T. M. Aminabhavi, J. Controlled Release, 2005, 108, 193-214. 21 R. Aleksandrowicz, B. Taciak and M. Krol, J. Physiol. Pharmacol., 2017, 68, 165-174.

22 Z. Yang, X. Wang, H. Diao, J. Zhang, H. Li, H. Sunc and Z. Guo, Chem. Commun., 2007, 33, 3453-3455.

23 T. R. Daniels, E. Bernabeu, J. A. Rodríguez, S. Patel, M. Kozman, D. A. Chiappetta, E. Holler, J. Y. Ljubimova, G. Helguera and M. L. Penichet, Biochim. Biophys. Acta, 2012, 1820, 291-317.

24 H. G. J. Alqaraghuli, S. Kashanian, R. Rafipour, E. Mahdavian and K. Mansouri, Philos. Trans. R. Soc., A, 2018, 46, S847-S854.

25 S. V. Torti and F. M. Torti, Nat. Rev. Cancer, 2013, 13, 342355.

26 V. J. Raja, K. H. Lim, C. O. Leong, T. S. Kam and T. D. Bradshaw, Invest. New Drugs, 2014, 32, 838-850.

27 M. M. Bradford, Anal. Biochem., 1976, 72, 248-254. 
28 A. I. Kuruppu, L. Zhang, H. Collins, L. Turyanska, N. R. Thomas and T. D. Bradshaw, Adv. Healthcare Mater., 2015, 4, 2816-2821.

29 J. C. Quilles, D. Y. Tezuka, C. D. Lopes, F. L. Ribeiro, C. A. Laughton, S. de Albuquerque, C. A. Montanari and A. Leitão, Exp. Parasitol., 2019, 200, 84-91.

30 J. C. Quilles, M. D. L. Bernardi, P. H. J. Batista, S. da Costa Martins Silva, C. de Melo Romero Rocha, C. A. Montanari and A. Leitão, Anti-Cancer Agents Med. Chem., 2018, 18, 1-9.

31 P. Ekblom, I. Thesleff, V. P. Lehto and I. Virtanen, Int. J. Cancer, 1983, 31, 111-117.

32 B. Subhadarshanee, A. Mohanty, M. K. Jagdev, D. Vasudevan and R. K. Behera, Biochim. Biophys. Acta, 2017, 1865, 12671273.

33 S. Dostalova, T. Cerna, D. Hynek, Z. Koudelkova, T. Vaculovic, P. Kopel, J. Hrabeta, Z. Heger, M. Vaculovicova, T. Eckschlager, M. Stiborova and V. Adam, ACS Appl. Mater. Interfaces, 2016, 8(23), 1443014441.

34 B. Ruozi, P. Veratti, M. A. Vandelli, A. Tombesi, M. Tonelli, F. Forni, F. Pederzoli, D. Belletti and G. Tosi, Int. J. Pharm., 2017, 518, 281-288.

35 M. Liang, K. Fan, M. Zhou, D. Duan, J. Zheng, D. Yang, J. Feng and X. Yan, Proc. Natl. Acad. Sci. U. S. A., 2014, 111, 14900-14905.

36 G. C. Baltazar, S. Guha, W. Lu, J. Lim, K. Boesze-Battaglia, A. M. Laties, P. Tyagi, U. B. Kompella and C. H. Mitchell, PLoS One, 2012, 7(12), 1-10.
37 L. Turyanska, T. D. Bradshaw, J. Sharpe, M. Li, S. Mann, N. R. Thomas and A. Patane, Small, 2009, 5(15), 1738-1741. 38 Z. Zhen, W. Tang, H. Chen, X. Lin, T. Todd, G. Wang, T. Cowger, X. Chen and J. Xie, ACS Nano, 2013, 7(6), 48304837.

39 E. Brauchle, S. Thude, S. Y. Brucker and K. Schenke-Layland, Sci. Rep., 2014, 4, 1-9.

40 H. Murad, M. Hawat, A. Ekhtiar, A. Aljapawe, A. Abbas, H. Darwish, O. Sbenati and A. Ghannam, Cancer Cell Int., 2016, 16(1), 1-11.

41 N. A. P. Franken, H. M. Rodermond, J. Stap, J. Haveman and C. van Bree, Nat. Protoc., 2006, 1(5), 2315-2319.

42 S. Valastyan and R. A. Weinberg, Cell, 2011, 147(2), 275-292.

43 M. Verdoes, K. O. Bender, E. Segal, W. A. van der Linden, S. Syed, N. P. Withana, L. R. Saman and M. Bogyo, J. Am. Chem. Soc., 2013, 135, 14726-14730.

44 V. Turk, V. Stoka, O. Vasiljeva, M. Renko, T. Sun, B. Turk and D. Turk, Biochim. Biophys. Acta, Proteins Proteomics, 2012, 1824(1), 68-88.

45 H. Kirschke, R. Eerola, V. K. Hopsu-Havu and D. Bro, Eur. J. Cancer, 2000, 36, 787-795.

46 A. Yamada, N. Ishimaru, R. Arakaki, N. Katunuma and Y. Hayashi, PLoS One, 2010, 5(9), e12894.

47 D. R. Sudhan and D. W. Siemann, Clin. Exp. Metastasis, 2013, 30, 891-902. 